\title{
Single-Incision Endoscopic Thyroidectomy by the Axillary Approach
}

\author{
Dosang Lee, MD, PhD, Yuhee Nam, MD, and Kiyoung Sung, MD, PhD
}

\begin{abstract}
Introduction: As endoscopic skills and instruments continue to improve, many surgeons have begun to pay more attention to minimally invasive surgical techniques. Ever since Gagner first described endoscopic neck surgery, various techniques for endoscopic thyroidectomy have been attempted to improve the cosmetic results therein. The invasiveness of conventional endoscopic thyroidectomy is its main disadvantage, because the procedure requires a wide dissection just to reach the target site. More recently, single-incision laparoscopic surgery has received favorable attention due to the reduction of both scars and postoperative pain in various surgical fields. In this article, we report the initial clinical experiences with single-incision endoscopic thyroidectomies (SIETs) that have been performed via the axillary approach.

Materials and Methods: We performed multiple SIETs via the axillary approach to overcome the known disadvantages of conventional endoscopic thyroidectomy. Four consecutive patients underwent SIETs that were undertaken using the standard laparoscopic instruments at our institution. In this study, we analyzed tumor size, operative time, length of hospital stay, complications, and cosmetic results.

Results: All patients were women and had undergone successful SIET operations. The mean age was $35.6 \pm 11.4$ years (range, 19-43 years), and the mean time of the operation was 160 \pm 19.2 minutes (range 145-185 minutes). There were no reported complications, and all the patients were very satisfied with the cosmetic results.

Conclusions: SIET via the axillary approach is safe and feasible for the treatment of patients with thyroid tumors.
\end{abstract}

\section{Introduction}

A $S$ THE DEVELOPMENT OF endoscopic skills and instruments continues to advance, minimally invasive surgical techniques have attracted favorable attention in all surgical fields. Ever since Gagner reported on the safety and effectiveness of endoscopic neck surgery in 1996, ${ }^{1}$ various types of conventional endoscopic thyroidectomies (CET) have been used to improve the cosmesis therein. The transaxillary approach, among the other reported routes, has a better cosmetic result due to the invisible resultant operative scar in the neutral position. We have performed CET by the axillary approach in about 350 patients with thyroid tumors and have confirmed its favorable cosmetic results; however, a CET procedure that is conducted via the axillary approach usually requires a 3- to 4-cm skin incision and an additional 5-mm incision for inserting trocars. Further, this procedure requires a wide dissection area to reach the target site from the axillary region. Recently, single-incision laparoscopic surgery has been developed and applied in a number of surgical fields, and therein, many reports have described better cosmetic re- sults and less wound pain. ${ }^{2-5}$ Thus, we performed singleincision endoscopic thyroidectomy (SIET) via the axillary approach to improve cosmetic results and minimize the invasiveness of CET. The aim of this article is to demonstrate our initial experience with SIET and evaluate its safety and feasibility.

\section{Materials and Methods}

Four consecutive patients underwent SIET by the axillary approach in our institution, which was performed by the same surgeon (K.Y.S.). Our indications for SIET are as follows: a benign tumor and no previous history of neck surgery or irradiation. All of the procedures were strictly based on the patient's individual decision after obtaining informed consent concerning the surgical risks and the possible conversion to open surgery or CET. We later retrospectively analyzed the medical records of all of the patients and evaluated the surgical outcomes of the SIET procedures, including the number of hospital days, operative time, complications, tumor size, and cosmetic results. The cosmetic result factor was evaluated

Department of Surgery, Bucheon St. Mary's Hospital, The Catholic University of Korea, Bucheon, Korea. 


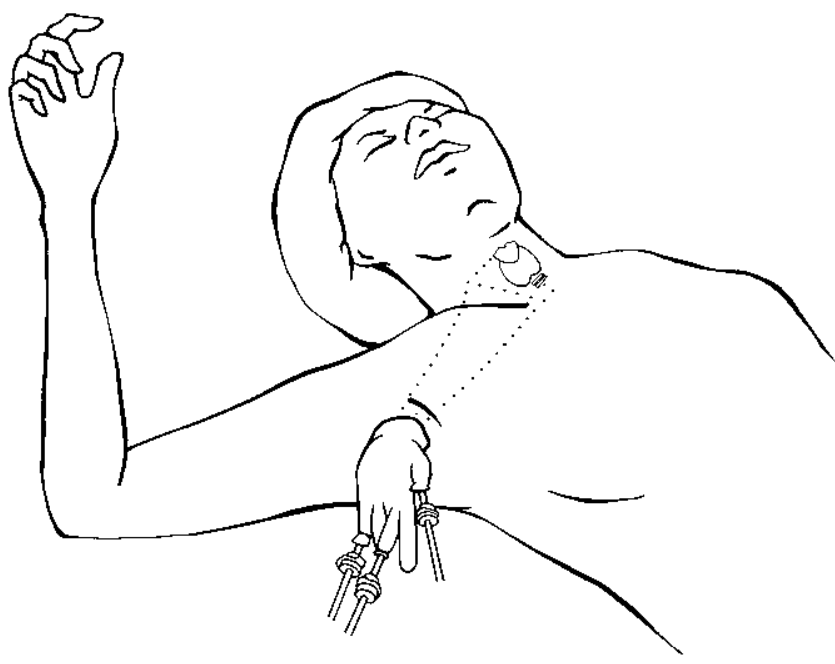

FIG. 1. Schema of single-incision endoscopic thyroidectomy.

by a verbal response scale, which had four options: 1 , extremely satisfied; 2 , satisfied; 3 , acceptable; and 4, dissatisfied. All the patients were asked about the cosmetic results 3 months after surgery.

\section{Surgical techniques}

Under general anesthesia, the patient was placed in a supine position with the neck slightly extended (Fig. 1). The arm on the side of the lesion was raised to expose the axilla. A diluted epinephrine solution (1: 300,000) was injected for vasoconstriction and hemostasis. A $2-$ to $2.5-\mathrm{cm}$ skin incision was then made along the skin crease of the axilla (Fig. 2). Dissection was carried out under direct vision to the upper portion of the pectoralis major muscle. The working space for this operation was created by gentle and blunt dissection with an acrylic bar. After adequate dissection, we made a singleport system using a double-ring wound retractor (Alexis ${ }^{\circledR}$; Applied Medical, Rancho Santa Margarita, CA) and a surgical glove. Three 5-mm trocars were inserted into the first, third,

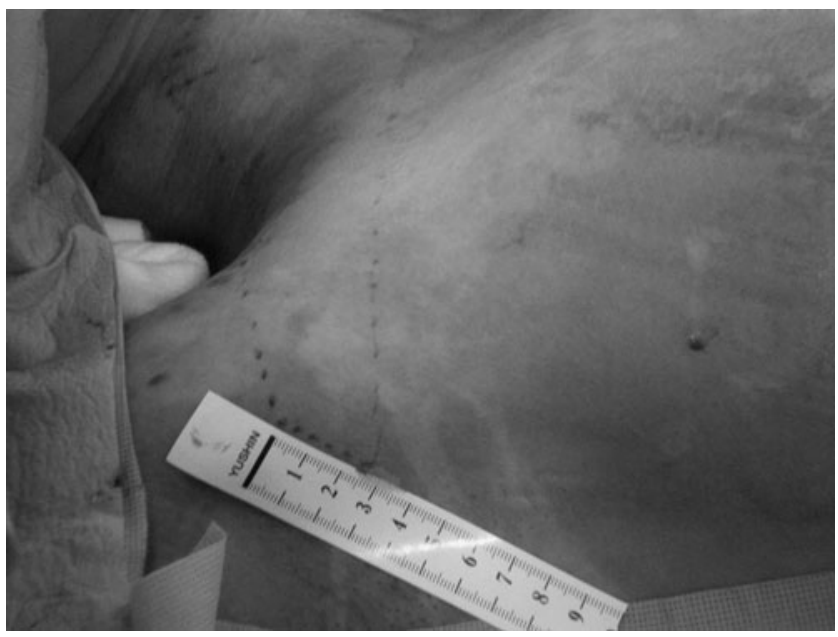

FIG. 2. Preparation of incision, which is $2.5 \mathrm{~cm}$.

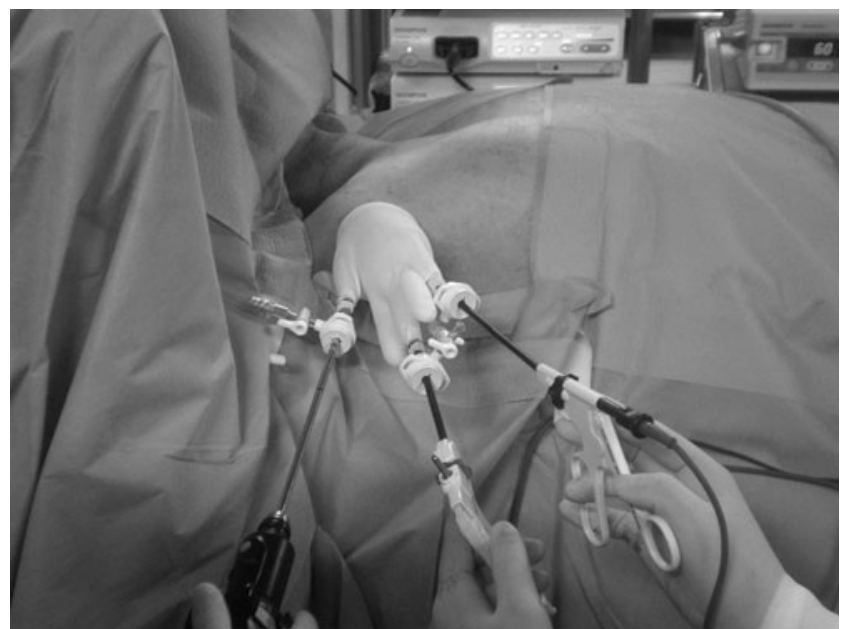

FIG. 3. Photograph of patient during single-incision endoscopic thyroidectomy.

and fifth fingers of the glove and then fastened with silk so as to prevent leakage of gas (Fig. 3). A double-ring wound retractor was inserted through the incision and rolled to cover and stretch it. The glove was latched on to the wound retract ring, which was rolled over it to provide a seal. $\mathrm{CO}_{2}$ gas was insufflated up to a pressure of $4-6 \mathrm{mmHg}$. A 5-mm flexible laparoscope (LTF-VP; Olympus, Tokyo, Japan) was then inserted through a 5-mm trocar. To create a sufficient operative field, we used electric cautery and endoscopic scissors for sharp dissections. After the sternocleidomastoid muscle and the strap muscle were identified, the medial border of the sternocleidomastoid muscle was dissected from the strap muscle via a Sonosurg (SonoSurg Scissors, 5-mm O.D., T3105; Olympus). After the thyroid gland was exposed, the strap muscle was superiorly retracted with 2-0 polyglactin (Vicryl, Ethicon, Johnson \& Johnson, Cincinnati, $\mathrm{OH}$ ) so as to enlarge an operative space. The lateral border was dissected by retracting the thyroid gland, and the middle thyroid vessels were divided and cauterized with the Sonosurg. The upper

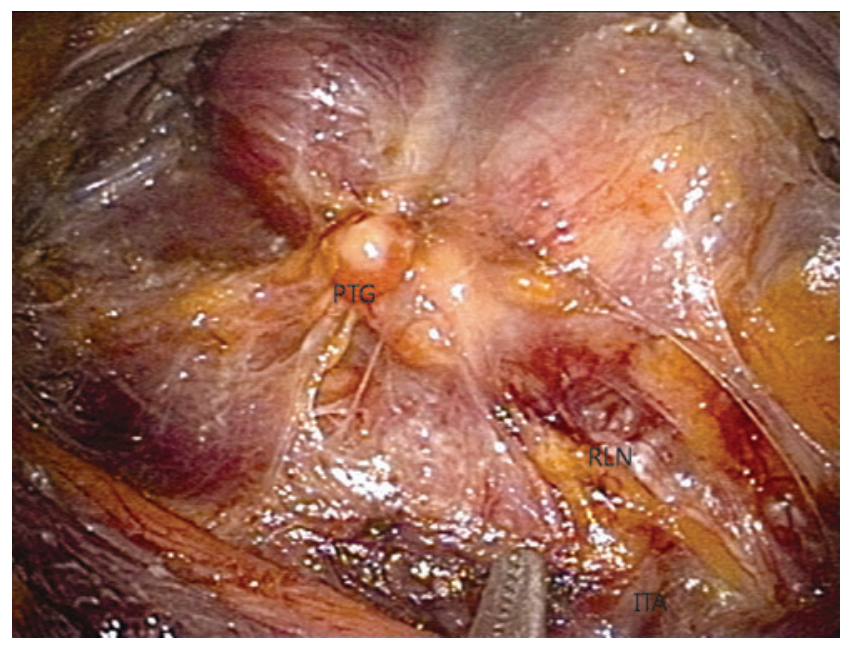

FIG. 4. Lateral view of right thyroid gland. PTG, parathyroid gland; RLN, recurrent laryngeal nerve; ITA, inferior thyroidal artery. 
pole was retracted downward and dissected. The superior thyroid vessels were identified and cauterized. The upper pole was carefully resected to avoid injuring the superior laryngeal nerve. The gland was medially retracted. Careful dissection was continued to identify the inferior thyroid artery and recurrent laryngeal nerve. Cauterization of the inferior thyroid artery close to the gland was necessary so as to preserve the nerve and parathyroid gland. After identification of the recurrent laryngeal nerve and parathyroid gland (Fig. 4), Berry's ligament was severed. The isthmus of the thyroid gland was dissected and resected from the trachea using the Sonosurg. The specimen was retrieved through the incision. After complete hemostasis, a closed suction drain was inserted.

\section{Results}

All the procedures were performed under the aforementioned conditions. There was no conversion to CET. All the patients were women, with a mean age of $35.6 \pm 11.4$ years (range 19-43 years). One patient had a follicular adenoma, and 3 patients had nodular hyperplasia (Table 1 ). The average length of the operation was $160 \pm 19.2$ minutes (range 145-185 minutes). The average size of the mass was $2.83 \pm 1.23 \mathrm{~cm}$ (range $2-4.6 \mathrm{~cm}$ ). Three patients were discharged on the second postoperative day and 1 patient on the third postoperative day due to discomfort at her drain site. There was no evidence of injury to the recurrent laryngeal nerve or parathyroid glands (Table 1), and there was no impairment of neck movement due to adhesion. All the patients were satisfied with their cosmetic results and had no hypertrophic scars (Fig. 5).

\section{Discussion}

Traditional thyroid surgery requires a transverse incision in the anterior lower neck. Such a scar results in a permanent cosmetic defect, frequent cervical hypesthesia, or paresthesia. Since the prevalence of thyroid disease is significantly higher in women, cosmetic outcomes are an even more important consideration in thyroid surgery. Since the first report of endoscopic neck surgery, many institutes have undertaken the development of new methods of endoscopic thyroid surgery. Various incision sites for endoscopic thyroidectomies have been used, such as the chest wall, axilla, breast, and submandibular areas. ${ }^{6-10}$

Ikeda et al. $^{6}$ have described several merits of the transaxillary approach in endoscopic thyroid surgery: First, there is an excellent cosmetic outcome due to the complete concealment of the incision site; second, the ipsilateral recurrent

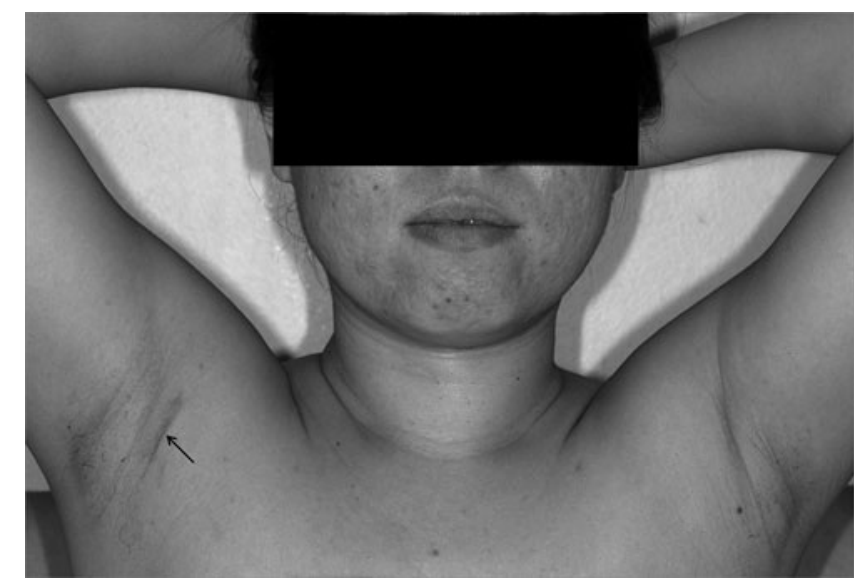

FIG. 5. Inconspicuous incision 3 months after operation. Scar is hidden by skin crease. Arrow indicates the scar.

laryngeal nerve and parathyroid glands can be easily identified; and third, the upper and lower poles of the thyroid can easily be manipulated. However, the transaxillary approach requires a large amount of tissue dissection to reach the target area. The operation time of endoscopic thyroidectomy was longer than conventional thyroidectomy, and some patients complained of wound pain. In addition, we experienced hypertrophic scarring at the site of the main incision and used an additional 5-mm trocar.

To overcome the pain and invasiveness, we reduced the incision size from 3-4 to $2-2.5 \mathrm{~cm}$ and applied single-incision endoscopic surgery so as to narrow the dissection area approaching the operation site. To carry out single-incision laparoscopic surgery, several port-access techniques have been developed ${ }^{2,11,12}$; however, there is still no commercial single-port access in Korea, and single-port devices have problems with medical insurance coverage. Thus, we used commonly available devices in laparoendoscopic surgery.

In terms of cosmoses, all the patients were satisfied with good cosmetic results and no hypertrophic scars. This is probably due to the reduced length of incision and the doublering wound retraction, which protected the wound from maceration and contamination.

In this article, we discuss two obstacles that relate to the successful performance of the SIET procedure. First, sometimes instrumental clashing interfered with the performance of the procedure. To avoid this problem, we used a streamlined 5-mm flexible scope (LTF-VP; Olympus). This scope substantially minimized instrumental crushing. We also

TABle 1. Patients' Characteristics

\begin{tabular}{lccccccc}
\hline $\begin{array}{l}\text { Patient } \\
\text { no. }\end{array}$ & Sex & $\begin{array}{c}\text { Age } \\
\text { (years) }\end{array}$ & Pathology & $\begin{array}{c}\text { Tumor size } \\
(\mathrm{cm})\end{array}$ & $\begin{array}{c}\text { OR time } \\
\text { (minutes) }\end{array}$ & $\begin{array}{c}\text { Hospital } \\
\text { stay (days) }\end{array}$ & $\begin{array}{c}\text { Cosmetic } \\
\text { result }\end{array}$ \\
\hline 1 & $\mathrm{~F}$ & 37 & FA & 4.6 & 185 & 2 & Nome \\
2 & $\mathrm{~F}$ & 43 & $\mathrm{NH}$ & 2 & 165 & 2 & None \\
3 & $\mathrm{~F}$ & 43 & NH & 2 & 145 & 3 & None \\
4 & $\mathrm{~F}$ & 19 & NH & 2.7 & 145 & 2 & None \\
\hline
\end{tabular}

${ }^{a}$ Extremely satisfied.

FA, follicular adenoma; $\mathrm{NH}$, nodular hyperplasia; OR, operating room. 
operated the instruments on two imaginary planes: an upper plane for scopes and a lower plane for other instruments. The use of instruments with different lengths helped reduce the incidence of operators fighting one hand with another. Undoubtedly, an understanding between the operator and the camera assistant is essential. ${ }^{13}$ Second, even small amounts of smoke caused serious interference with the visual field due to the very narrow working space. The Sonosurge's power was very helpful in this matter. Although weaker than a harmonic scalpel, the amount of smoke produced by this instrument is less than that emitted by the harmonic scalpel.

In our experience, a surgeon who is an expert with CET will perform SIET without any difficulty. With time and further development of endoscopic instruments, the remaining technical difficulties will be overcome. Although a larger series of patients and prospective studies is necessary, we fully expect that SIET will enhance the cosmetic results of thyroid surgery and minimize the invasiveness of CET.

\section{Conclusion}

Although there are some limitations of SIET via the axillary approach, this method is safe and feasible without any new instrumentation needs. SIET may become the alternative procedure for the treatment of patients with thyroid tumors.

\section{Authors' Contributions}

Dosang Lee: Prepared the manuscript and photograph.

Yuhee Nam: First assistant of the operation and literature review.

Kiyoung Sung: Revised the manuscript and literature review.

\section{Disclosure Statement}

No competing financial interests exist.

\section{References}

1. Gagner M. Endoscopic subtotal parathyroidectomy in patients with primary hyperparathyroidism. Br J Surg 1996; 83:875.

2. Merchant AM, Cook MW, White BC, et al. Transumbilical gelport access technique for performing single incision laparoscopic surgery (SILS). J Gastrointest Surg 2009;13:159-162.
3. Hong TH, You YK, Lee KH. Transumbilical single-port laparoscopic cholecystectomy: Scarless cholecystectomy. Surg Endosc 2009;23:1393-1397.

4. Pappalepore N, Tursini S, Marino N, et al. Transumbilical laparoscopy-assisted appendectomy (TULAA): A safe and useful alternative for uncomplicated appendicitis. Eur J Pediatr Surg 2009;12:383-386.

5. Castellucci SA, Curcillo PG, Ginsberg PC, et al. Single port access adrenalectomy. J Endourol 2008;22:1573-1576.

6. Ikeda Y, Takami H, Sasaki Y, et al. Endoscopic neck surgery by the axillary approach. J Am Coll Surg 2000;191:336-340.

7. Park YL, Han WK, Bae WG. 100 cases of endoscopic thyroidectomy; breast approach. Surg Laparosc Endosc Percu$\tan$ Tech 2003;13:20-25.

8. Kim JS, Kim KH, Ahn CH, et al. A clinical analysis of gasless endoscopic thyroidectomy. Surg Laparosc Endosc Percutan Tech 2001;11:268-272.

9. Shimizu K, Akira S, Jasmi AY, et al. Video-assisted neck surgery: Endoscopic resection of thyroid tumors with a very minimal neck wound. J Am Coll Surg 1999;188:697-703.

10. Ohgami M, Ishii S, Arisawa Y, et al. Scarless endoscopic thyroidectomy: Breast approach for better cosmesis. Surg Laparosc Endosc Percutan Tech 2000;10:1-4.

11. Remzi FH, Kirat HT, Kaouk JH, et al. Single-port laparoscopy in colorectal surgery. Colorectal Dis 2008;10:823-826.

12. Rane A, Rao P, Bonadio F, et al. Single port laparoscopic nephrectomy using a novel laparoscopic port (R-port) and evolution of single laparoscopic port procedure (SLIPP). J Endourol 2007;21:A287.

13. Tacchino R, Greco F, Maetra D. Single-incision laparoscopic cholecystectomy: Surgery without a visible scar. Surg Endosc 2009;23:896-899.
Address correspondence to: Kiyoung Sung, MD, PhD Department of Surgery Bucheon St. Mary's Hospital The Catholic University of Korea Sosa-dong, Wonmi-Gu Bucheon City 420-717 Kyunggi-Do Korea

E-mail: skyhfh@catholic.ac.kr 